\title{
A Delivery Approach Modeling for Urban Freight Restocking
}

\author{
Agostino Nuzzolo, Umberto Crisalli and Antonio Comi \\ Department of Enterprise Engineering, “Tor Vergata” University of Rome, Italy
}

\begin{abstract}
This paper proposes a modeling system developed in order to analyze the urban freight transport and logistics within urban and metropolitan areas. A review of models developed to simulate this segment of mobility is also reported. The review analysis highlights the limits of models for the ex-ante assessment of city logistics measures. For this reason this paper proposes a new modeling system approach for the assessment of city logistics measures. It is made of different steps approaching problems related to: quantity OD (Origin-Destination) flows, restocking type OD flows, delivery OD flows, delivery OD flows for time slice and vehicle type, and vehicle OD flows. This modeling system has been specified and calibrated using some surveys carried out in the inner area of Rome where more than 500 truck drivers and more than 600 retailers have been interviewed.
\end{abstract}

Key words: Urban goods movements, urban freight demand model, delivery approach, city logistics assessment.

\section{Introduction}

The increase of freight transportation in urban and metropolitan areas contributes to congestion, air pollution, noise and to the increases in the logistic costs, and hence to the price of products. In addition, increasing flows on road networks, as well as the combination of different types of vehicles, imply an increase of the risk of accidents. The investigation of cost externalities requires an efficient freight distribution system as it plays a significant role in the competitiveness of an urban area, and it is an important element in the urban economy, in terms of both incomes it generates and employment levels it supports.

From public administration point of view, the most important aspect is that of mitigating the social costs generated by freight mobility in the urban area. These costs are mainly connected with the impact on traffic congestion of vehicles circulating for freight transport,

Corresponding author: Antonio Comi, $\mathrm{PhD}$, assistant professor, research fields: development and application of models and methods for the analysis and the design of freight and passenger transport systems at urban and extra-urban scale. E-mail: comi@ing.uniroma2.it. as well as of the road capacity reduction caused by vehicle stops for loading or unloading operations. Thus, in order to make urban mobility more sustainable, measures to reduce the environmental impact of freight transport have to be implemented. Last experiences of implemented measures to reduce the negative effects of freight transport have often been proved ineffective. In fact, many of them have been implemented without an ex-ante assessment supported by simulation models and have not always been effective. However, several authors agree that the proposed approaches are not yet fully validated and in any cases they did not provide the expected results. The lack of interest by local authorities for this segment of mobility implies a shortage of data, for which only few experiences are characterized by the support of comprehensive surveys [1].

Simulation models for urban freight transport play a key role as it allows us to estimate and evaluate performances and impacts generated by urban freight measures. A review of the various measures implemented and their results have been carried out by COST 321 [2], City Ports [3], BESTUFS [4] and Russo and Comi [5], even if the proposed 
classifications are mainly descriptive and are not useful for modeling implementation in the sense of the ex-ante assessment. A possible classification of measures can consider the following three classes:

- physical; this class includes measures related to areas that can be reserved for freight operations (e.g., logistic nodes to optimize freight distribution in metropolitan/urban areas like urban consolidation centers);

- governance; in this class we can find traffic regulations (e.g., time windows, heavy vehicle network, road-pricing, maximum parking time, maximum occupied surface and specific permission, incentives to switch from own account to third parties), and measures related to the introduction of new standards for transport units (equipment measures), such as low-emission vehicles;

- technological (such as Intelligent Transportation Systems - ITS); this class includes traffic information systems, systems for route optimization, freight capacity exchange, tracing and tracking;

Starting from this classification, in the following the developed modeling system for urban freight transport and logistics will be analyzed, trying to identify the possibility to assess impacts generated by the implementation of some city logistics measures (section 2). The analysis focuses on the policy needs that urban freight models might address. Thus, a modeling system that allows us to address these needs will be proposed (section 3). Section 4 reports the results of calibration and validation of the modeling system to a real case. Finally, section 5 summaries some conclusions and further developments of this work.

\section{The State-of-the-Art on Urban Freight Transport Modeling}

In addition to papers proposing analysis methods and models for urban goods movements, papers with classifications of models according to some criteria have been proposed: Ogden [6] classifies models according to the reference unit (commodity-based or truck-based); Regan and Garrido [7] identifies step and macro-economic models; Ambrosini and Routhier [8] group models by the country in which they were proposed and applied; Ambrosini et al. [9] analyze urban freight policy-oriented modeling in Europe. Finally, Chow et al. [10] classify available models into seven classes, and describe modeling concepts and case studies. For recent developments on urban freight methods and models, the reader can also refer to Taniguchi and Thompson [11] and Comi et al. [12].

The need of finding solutions for the forecasting and management of freight vehicles in urban areas is stimulating the investigation of models to estimate OD (Origin-Destination) matrices and vehicle flows on the links of the road network. Most proposed models have been developed within the sequential modeling approach considering three categories of models based on truck, commodity and delivery (Fig. 1).

The truck-based models consider the trip of freight vehicles as reference unit. The basic structure is characterized by a first step consisting in models providing the number of freight vehicles attracted or generated by individual zones. The next step is a distribution model which provides the OD matrices in vehicles to be loaded on the road network.

These types of models have been proposed by Ogden [6], Spielberg and Smith [13], Hunt and Stefan [14], and Wang and Holguin-Veras [15].

Although, truck-based models estimate directly trips of freight vehicles, they are suitable to be used for the simulation of the current scenario but they are difficult to be used for forecasting analysis. Truck-based models have the advantage of the ease of data gathering (e.g., using automatic traffic counts) which facilitates the calibration and validation, but they are not able to account properly for changes in the mechanisms underlying demand generation. It is important to note that they do not allow to follow the mechanism that determine the freight demand and, secondly, these type of models could well reproduce 


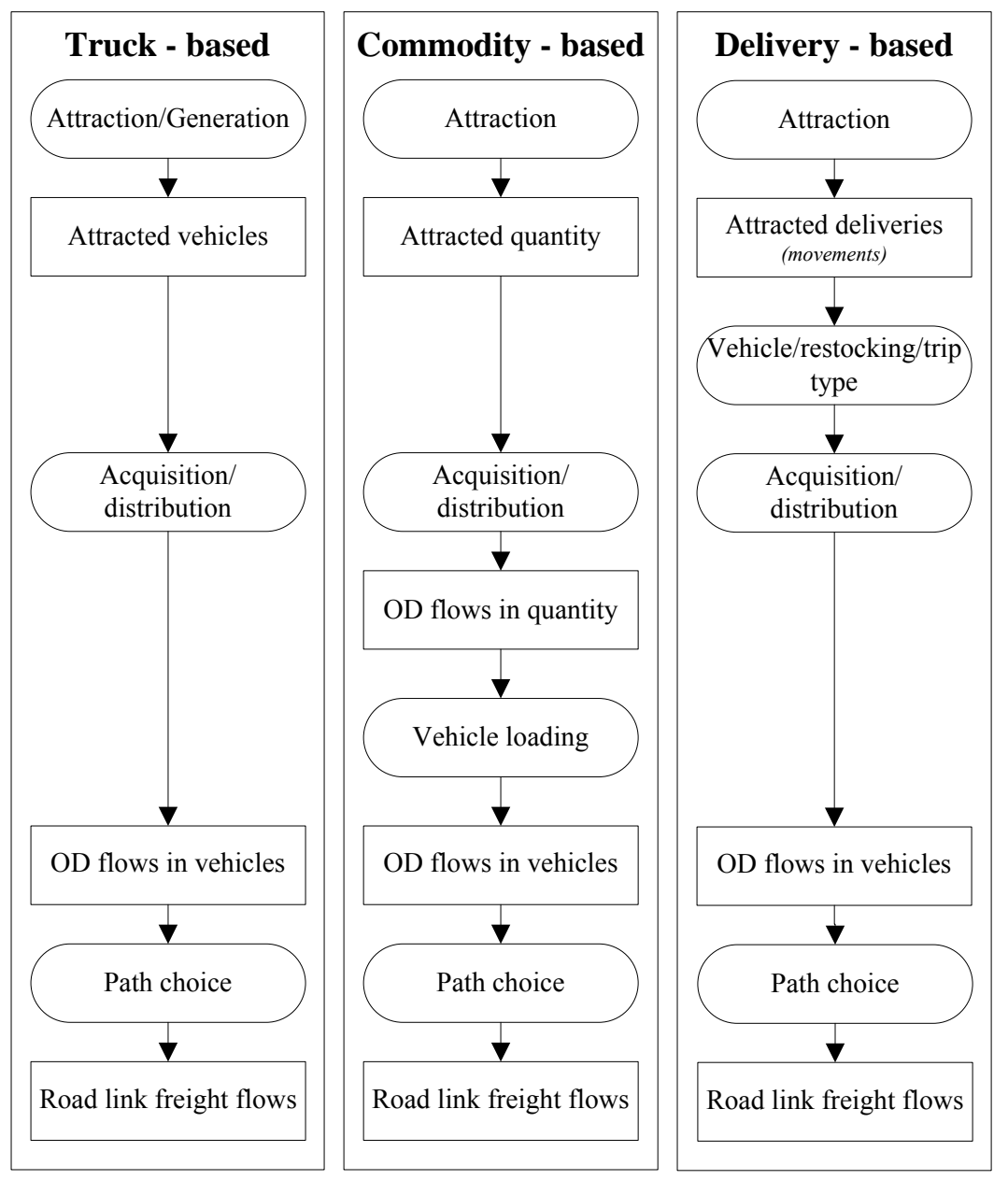

Fig. 1 Classification of possible structures for urban freight modelling.

round trip (one origin-one destination), but fail in the trip chain simulation. In fact, this class of models ignores the possibility to take into account the different origins of trips that compose the trip-chain (journey) and for this reason they are not suitable to be used for ex-ante assessment analysis of city logistics measures.

For these reasons the main interest of the research in the field of urban freight transport is focused on the other modeling approaches which are based on commodity and delivery. The estimation of OD matrices by commodity-based models is usually carried out by a sequence of models:

- $\quad$ attraction model, which provides the commodity flows attracted by each zone in function of some socio-economic data;
- distribution/acquisition model, which provides the zone from which the commodity flows originate and, hence, it allows to determine the quantity OD flows; this model allows us to investigate how city logistics measures related to Level of Service attributes (LoS) could modify the choice of origin (e.g., the choice of wholesaler) from where the freight arrives to the study area;

- $\quad$ vehicle loading model, which receives as input the quantity OD flows and converts them into vehicles.

Commodity-based models allow us to capture the mechanisms underlying the generation of freight transport demand, and new studies have proposed to modify the general modeling approach in order to include the possibility to simulate the restocking process [16], the vehicle holding choice [17] and to 
follow the journey within the urban area (trip-chain; [18-20]). These integrations have provided new perspectives that allow us to better evaluate how city logistics measures can influence the urban freight demand (e.g., incentives to switch from own account to third parties).

Models developed to estimate the OD matrices within the commodity-based approach have been given by Ogden [6] that proposes some applications to the city of Melbourne. Other applications of this class of models have been proposed by Oppenheim [21], Munuzuri et al. [22], Nuzzolo et al. [23], Russo and Comi [24].

Recently, the delivery approach has been proposed to better simulate the decisional process of urban freight trip definition. It focuses on movements/deliveries (pick-ups and deliveries); the use of delivery as reference unit allows to identify easily the movements to each economic activities (origin and/or destination) of study area, as well as it allows to have a direct link between generators and transport operators; moreover, it allows to locate and measure the duration of each stops per vehicle and to evaluate and to analyze the parking conditions [25]. The proposed modeling approach consists of a sequence of descriptive-statistic models that allow us to simulate the delivery flows as depicted in Fig. 1. This modeling structure allows us to follow the decisional process underlying the definition of tours and thus, it is a good tool in the ex-ante assessment of city logistics measures influencing this step, even if this kind of models fail in the evaluation of impacts determining changes in the mechanisms underlying freight demand.

From the analysis of the previous recalled studies it may be noted that many of them do not allow to follow the mechanism that provide the definition of OD matrices in vehicles starting from OD flows in quantity: they are not used (or usable) to forecast the impacts of implementing transportation measures at an urban scale. The movement of load trips is similar to the commodity movement in the cases of round trips (one origin - one destination, i.e., zero order trip chains), because the origin and destination of both commodity and truck are the same. However, the OD matrices of commodity flows and vehicle flows are quite different when trips involve many destinations (one origin - many destinations, i.e., the trip is a part of $n$-th order trip chains). Freight vehicles usually behave making long tours made of multiple trips (in order to perform multiple deliveries), as well as trips within a tour (journey) are related according to the underlying logistic decisions.

The recalled models were developed to simulate some aspects of the restocking process and do not allow to investigate each trip of the same journey (tour). Ignoring these interactions may be appropriate when freight is moved by round trip or for empty truck trips, but it is obviously inappropriate in many urban freight situations.

In order to overcome these limits, it should be necessary to have a modeling system that considers as reference unit both the quantity and the delivery. Quantity allows us to follow the mechanism underlying freight demand, and delivery allows us to follow better the decision process of trip-chain definition. For this reason, a new modeling system is here proposed aiming at estimating attracted commodity flows in order to support a given freight demand within urban study area. The modeling system is made of different steps approaching freight transport problems related to: quantity OD flows, restocking type OD flows, delivery OD flows, delivery OD flows for time slice and vehicle type, and vehicle OD flows.

This paper proposes a modeling system to simulate goods movements at an urban scale combining commodities, deliveries and vehicles flows. In fact, for a better conversion of quantities into vehicles, we propose a through-step which estimates freight OD matrices in terms of deliveries. This approach allows us to follow the sequence of activities undertaken 
during the journey (deliveries and pick-up) and to define a tool that allows the ex-ante assessment of city logistics measures.

\section{The Proposed Modeling System}

The proposed modeling system allows us to estimate the OD flows in terms of quantities, deliveries and vehicles used for restocking the study area for different freight types, as follows:

- quantity $O D$ flows: freight $\mathrm{OD}$ matrices in quantity (e.g., tons) are estimated starting from socio-economic data;

- restocking-type OD flows: freight OD matrices in quantity are split in terms of restocking type (e.g., retailer in own account, wholesaler in own account and by carrier);

- delivery $O D$ flows: starting from the restocking type OD flows, the model gives flows of deliveries for each $o d$ pair; the delivery step is modeled through the evaluation of freight quantity delivered (shipment size) by different identified restocking types;

- delivery OD flows for time slice: the delivery OD flows are characterised for target time;

- delivery $O D$ flows for vehicle type: the delivery OD flows are split in terms of vehicle type (e.g., Light Goods Vehicles, Heavy Goods Vehicles);

- vehicle $O D$ flows: the delivery OD flows for vehicle type are converted in OD vehicle flows taking into account the origin of each truck trip belonging to the same journey (tour).

Each of the previous steps is modeled as detailed in the following.

\subsection{Quantity OD Flows}

The average flow of freight quantity of type $s$ between zones $o$ and $d$ in time period $h$ (e.g., day), $Q_{o d}^{s h}$, is expressed as:

$$
Q_{o d}^{s h}=Q_{d d}^{s h} p[o / d s h]
$$

where

- $Q_{d}^{s h}$ is the attraction demand obtained by an attraction model, which represents the average quantity of freight of type $s$ attracted by zone $d$ in time period $h$;

- $p[o / d s h]$ is the share of freight type $s$ that, attracted by zone $d$ in time period $h$, comes from zone $o$ (e.g., production place/firm, distribution centre, warehouse, etc.); it represents the acquisition share (probability) obtained by an acquisition model.

\subsubsection{Attraction Model}

The attraction model allows us to obtain the average flow of freight that arrives to each zone of the study area in order to satisfy the end-consumer demand. In fact, as confirmed by several studies, the urban and metropolitan areas are mainly interested by freight flows destined to final consumption. In general, each end-consumer can purchase the needed goods in different retailers or, in the case of some freight types, she/he can buy them in commercial concerns (e.g., bar, restaurant, and so on). Thus, in order to estimate the freight flows attracted in a time period $h$, we can assume to measure the attraction power of each zone with the number of retailers, or employees at sales of the area. Let be $i$ the class of generic retailer or employee. Average quantity flow of freight type $s$ attracted by zone $d$ in time $h, Q_{d}^{\text {sh }}$, can be expresses as follows:

$$
Q_{d}^{s h}=\sum_{i} n^{i}[s d] \cdot m^{i}[d s h]
$$

where

$n^{i}[s d]$ is the number of retailers or employees at sales (e.g., employees at bar, at shops) of class $i$ in activities related to freight type $s$, which are located in zone $d$;

$m^{i}[d s h]$ is the average quantity of freight type $s$ in time period $h$ attracted by each retailer or employee at sales located in attraction zone $d$.

The average quantity $m^{i}[d s h]$ can be expressed as a function, typically linear, of variables $\left(X_{j d}^{i}\right)$ corresponding to the freight type $s$ and the attraction zone $d$ :

$$
m^{i}[d s h]=\sum_{j} \beta_{j} X_{j d}^{i}
$$




\subsubsection{Acquisition Model}

The acquisition model simulates the choice of an origin among possible alternatives to bring the freight sold in shops including also commercial concerns (e.g., bar, restaurants, and so on). The decision-makers involved in the acquisition process are assumed to be the restocker (e.g., retailer or distributor).

Given the attraction (destination) zone $d$, the acquisition model allows us to define the zone from which freight arrives. Typically, the choice of the acquisition zone is simulated by Random Utility Models (RUM, e.g., multinomial logit models).

The probability $p[o / d s h]$ that freight type $s$ attracted by zone $d$ in time period $h$ comes from zone $o$ (e.g., places where production place/firm, distribution centre, warehouse are located), is given by:

$$
p[o / d s h]=\exp \left(V_{o}\right) / \sum_{o^{\prime}} \exp \left(V_{o^{\prime}}\right)
$$

where $V_{o}$ is a function of attributes of possible origins in relation to zone $d$ and freight type $s$ (e.g., number of wholesaler at zone $o$ for freight type $s$ ).

This step allows taking into account the variation of LoS (Level-of-Service) attributes (e.g., travel time and cost) due to the implementation of physical city logistics measures, such as Urban Distribution Centers, or governance measures (e.g., time windows, road-pricing, parking restrictions). The implementation of ITS measures could influence the origin choice, because, for example, traffic information systems and systems for route optimization are related to the expected generalized travel cost.

\subsection{Restocking-type OD Flows}

Freight can be transported and, thus, each retailer can be restocked in different ways:

- directly by the herself/himself (retailer/receiver) in own account $(r=$ retailer $)$;

- by the wholesaler or distributor (sender) in own account ( $r=$ restocking centre);

- $\quad$ by a carrier $(r=$ carrier $)$.
The restocking step allows us to investigate which type of restocking is chosen to move the freight from zone $o$ to zone $d$. The restocker is here assumed to be the decision-maker of the restocking process.

The average quantity flow of freight type $s$ attracted by zone $d$ and coming from zone $o$ in time $h$ with restocking type $r, Q_{o d}^{s h}[r]$, can be expresses as follows:

$$
Q_{o d}^{s h}[r]=Q_{o d}^{s h} p[r / o d s h]
$$

where $p[r / o d s h]$ is the probability estimated by a restocking model; it represents the probability that freight of type $s$ is transported by restocking type $r$ from zone $o$ to zone $d$; it can be expressed by a Random Utility Model (e.g., multinomial logit model), as:

$$
p[r / o d s h]=\exp \left(V_{r}\right) / \sum_{r^{\prime}} \exp \left(V_{r^{\prime}}\right)
$$

where $V_{r}$ is a function of attributes which characterize the restocking type $r$ with respect to all possible alternatives $r$ '. The systematic utility function $\left(V_{r}\right)$ can include variables representing the utility to have restocking by the given type $r$. Examples of attributes associated with $V_{r}$ are variables related to freight types and/or variables associated with services provided by a specific restocking type.

This step allows us to evaluate the impacts due to the implementation of governance measures, such as incentives to switch from own account to third parties and so on.

\subsection{Delivery OD Flows}

This step simulates the average flow of deliveries $N D_{o d}^{s h}[r]$ with their relevant characteristics between the zone $o$ and the zone $d$ in a time period $h$ (average delivery flow).

This step receives inputs from previous steps and takes into account the characteristics of freight type $s$ (e.g., fruit, clothing), restocking type $r$ (retailer, restocking center, carrier) and the average freight quantity delivered $(q)$, providing as output the number 
of deliveries needed to transport the estimated freight quantity.

The number of deliveries of freight type $s$ depends on the average quantity delivered $(q)$ carried out by restocking type $r$ on $o d$ pair. The average flow of deliveries $N D_{o d}^{s h}[r]$ can be expresses as:

$$
N D_{o d}^{s h}[r]=Q_{o d}^{s h}[r] / q[r s]
$$

where

- $Q_{o d}^{s h}[r]$ is the average freight quantity flow of freight type $s$ on $o d$ pair by restocking type $r$;

- $q[r s]$ is the average quantity of freight $s$ delivered with restocking type $r$.

The average freight quantity $q[r s]$ is a result of a complex decisional process depending on several attributes that can be modified by governance measures (e.g. interventions that modify travel costs or permitted vehicles); it can be expressed as:

$$
q[r s]=\sum_{y} y \cdot p[y / s]
$$

where $p[y / s]$ is the probability of delivering the quantity $y$ of freight type $s$. This probability can be expressed as a function of attributes related to freight type, restocking type and LoS attributes. The delivered quantity $y$ is a discrete variables and different classes of shipment dimensions can be identified (e.g., $y$ is less than 0.5 tons).

This step also allows taking into account how equipment measures can influence the composition of truck loads, such as restriction on vehicle type access (e.g., gross laden weight more than a given value).

\subsection{Delivery OD Flows for Time Slice}

Freight shipments are subject to time constraints at both origin and destination. At the origin constraints are due to the organization of the production process, while at the destination (within the urban area) the constraints are associated with the traffic and customer (retailer) constraints.

The delivery OD flows per time slices, $N D_{o d}^{s h}[r \tau]$ can be expressed as:

$$
N D_{o d}^{s h}[r \tau]=N D_{o d}^{s h}[r] \cdot p[\tau / o d s h]
$$

where $p[\tau / o d s h]$ is the probability of receiving deliveries in time slice $\tau$, which can be obtained by a delivery time model.

In many cities around the world and as confirmed by our test cases (see section 4) and the literature [26], time is constrained by governance regulations: the public authorities define one or two time windows (e.g., one in the morning between 8:00 and 10:00 am and one in the afternoon). For this reason, the delivery time model is generally a statistic-descriptive model. Although, it can be expressed within the Random Utility Theory as:

$$
p[\tau / \text { ods } h]=\exp \left(V_{\tau}\right) / \sum_{\tau^{\prime}} \exp \left(V_{\tau^{\prime}}\right)
$$

with $V_{\tau}$ is a function of attributes which characterize the time slice $\tau$ respect to all possible alternatives $\tau^{\prime}$. The systematic utility function $\left(V_{\tau}\right)$ can include variables representing the utility related to the Desired Departure Time (DDT), which represents the time at which the restocker wishes to depart from the origin, or to the Desired Arrival Time (DAT), which represents the times at which the restocker wishes to arrive at his/her destination (delivery point or stop). For example, the DAT is not just one moment, but a time window in which deliveries (vehicles) can arrive at shops without suffering any penalty. If a vehicle arrives before, it must wait until its time window begins and so it pays a cost. If the vehicle is late, it must pay a penalty proportional to time delay. Some studies of this type of penalty have been developed for freight and the total early/late penalty is estimated by a probabilistic model $[27,28]$.

This step allows us also to investigate how governance policies (e.g., time windows) or ITS (e.g., traffic information) can influence the target time.

\subsection{Delivery OD Flows for Vehicle Type}

Movements of deliveries can happen by using different types of vehicles (e.g., Light Goods Vehicles, Heavy Goods Vehicles).

The delivery od flow made using the vehicle type $v$ can be expressed as: 


$$
N D_{o d}^{s h}[v \tau r]=N D_{o d}^{s h}[r \tau] \cdot p[v / \tau q r o d s h]
$$

where

- $\quad N D_{o d}^{s h}[r \tau]$ is the number of deliveries of freight type $s$ carried out by restocking type $r$ on $o d$ pair characterized by the shipment size $q$;

- $\quad p[v / \tau q r o d s h]$ is the probability that deliveries use vehicle type $v$.

The decision-maker involved in this process depends on the type of restocking (retailer, wholesaler/ distributor and carrier).

The vehicle choice is a typical example of a travel choice that can be influenced by the implementation of city logistics measures. This choice depends on the characteristics of the delivery (e.g., freight type), characteristics of involved decision-maker, as well as on features of the urban transport system (LoS attributes and constraints to city access).

RUM (e.g., multinomial logit model) can be used to simulate the choice of vehicle type $v$. The probability of using vehicle type $v$ can be expressed as:

$$
p[v / \tau \operatorname{rods} h]=\exp \left(V_{v}\right) / \sum_{v^{\prime}} \exp \left(V_{v^{\prime}}\right)
$$

where $V_{v}$ is the systematic utility function associated to the use vehicle type $v$ for moving deliveries on the od pair.

The vehicle type choice model allows us to assess impacts due to the implementation of some governance measures related to the equipment in the field of city logistics, such as access restrictions to some classes of vehicles subject to environmental standards or laden weight.

\subsection{Vehicle OD Flows}

This step allows us to convert the delivery OD flows for vehicle type into vehicle OD flows. It provides the OD vehicle matrices in vehicles.

Referring to OD matrices in vehicles, the reader should consider that freight vehicles usually behave planning long tours made of multiple trips, and trips of a given tour/journey are defined according to logistic decisions. This feature breaks down some of the typical assumptions of the traditional step approach (e.g., traditionally used for passengers) as well as, for example, that trips are independent, or that trips between an origin-destination $(o d)$ pair are only related to the zonal attributes and to the travel cost of the corresponding od pair. Therefore, it implies that specific models for tours in urban freight demand forecasting are needed.

Starting from the outputs of previous steps (delivery OD matrices for vehicle type), the estimation of vehicle OD matrices can be carried out by using two different approaches:

- tour-based approach; it is an aggregate approach and it provides a sequence of behavioral models that allows to simulate choices of decision-makers (e.g., retailer, wholesaler, carrier) involved in the definition of the sequence of trips (tour/journey);

- micro-simulation approach, based on micro-simulation and optimization models, which simulate the urban freight distribution strategies of a generic player (decision-maker) belonging to the group of players located in a traffic zone; then, standard procedures extend results of individual simulation to the whole population are used.

\subsubsection{Tour-based Approach}

The tour-based approach aims at reproducing the choice structure of freight transport; it simulates the dependences exiting among successive trips of the same journey. It implies that each destination will be chosen according to the previous and following destinations by considering the number of stops as a whole. In order to implement this approach it is important to understand the constraints linking all the choices of the decision-makers.

This approach is more suitable for a transport planning point of view. In fact, it allows us to simulate the average behavior of decision-makers (e.g., retailer, wholesaler), and it is capable to capture the underlying decision-making process which generates vehicle operations and, hence, freight tours.

Considering the different decision-makers and following the sequence of choices done by each of them, the modeling structure receives as input the 
delivery OD matrices for vehicle types, and gives as output freight tours/journeys satisfying the given OD matrices that allow us to define the vehicle OD flows. The modeling system is structured as follows (Fig. 2): - definition of the order of trip chain (e.g., round trip or zero order trips chain); this step allows us to define the order of trip chain (tour) serving each zone;

- choice of the sequence of destinations; this step allows us to estimate the set of zones served in each tour.

The first model (trip chain order model) allows us to define the average order of trip chain. In particular, it allows us to disaggregate the flow of deliveries $N D_{o d}^{s h}[v \tau r]$ in order to take into account the number of stops that characterize the undertaken tour/journey. The flows of deliveries undertaken with trip chain of $n$-order can be expressed as:

$$
N D_{o d}^{s h}[n v \tau r]=N D_{o d}^{s h}[v \tau r] \cdot p[n / v \tau \text { qrodsh }]
$$

where

- $\quad N D_{o d}^{s h}[n v \tau r]$ is the flows of deliveries restocked with $n$ order trip chain;

- $p[n / v$ qrodsh $]$ is the share of the deliveries restocked on $o d$ pair which are undertaken by $n$-order trip chain; typically, this model is a statistic-descriptive one that expresses the number of trips ( $n$-order trip chain) belonging to each tour/journey as a function of the used vehicle type and the dimension of each delivery (shipment size, $q$ ).

Given the order of each trip chain, it is important to define the sequence of destinations followed for restocking. The definition of the sequence of destinations can be simulated by Random Utility Models (e.g., multinomial logit) as follows:

$$
p\left[d_{j} / d_{1} \ldots d_{j-1} n \tau v r o s h\right]=\exp \left(V_{d_{j}}\right) / \sum_{d_{j}^{\prime}} \exp \left(V_{d_{j}}\right)
$$

where

- $\quad p\left[d_{j} / d_{1}, \ldots d_{j-1} n v r o s h\right]$ is the destination (delivery stop) choice model expressing the probability of choosing zone $d_{j}$ after visiting the zones $d_{1}, d_{2}, \ldots, d_{j-1}$ with a tour (journey) with $n$ stops starting from zone $o$;

- $V_{d_{j}}^{s h}$ is the systematic utility function related to consider zone $d_{j}$ as the next destination of the tour (journey).

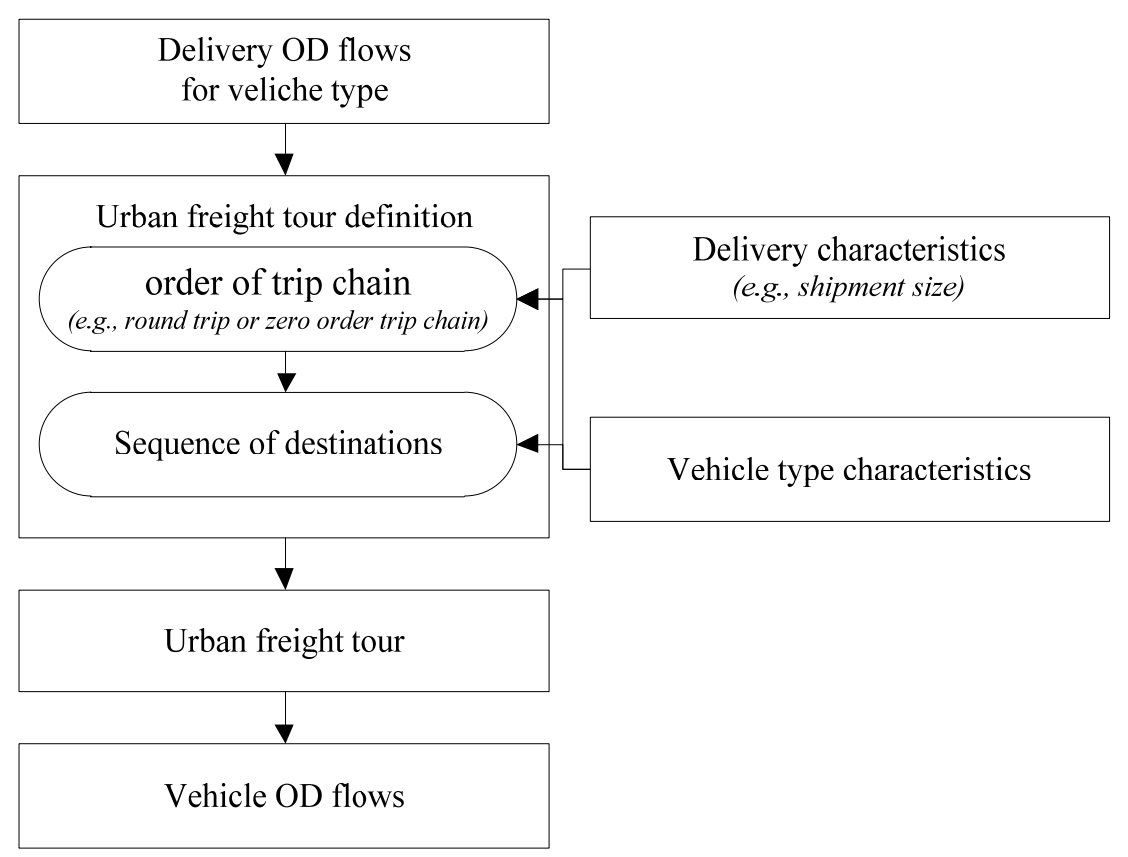

Fig. 2 Example of tour-based approach. 
Sometimes, the analyst is required to provide a first estimation truck of flows within the urban study area by using few available data. Thus, using a particular zoning of the area it is possible to convert the delivery OD flows for vehicle type to vehicle OD flows assuming that all deliveries are done in the same traffic zone (average quantity approach). It is based on the assumption that who restocks, organizes her/his tours trying to serve all customers closely located. For example, in Italy the restockers usually use the zoning related to zip code in order to organize their restocking tours. This assumption means that:

- the retailer brings all the freight sold in her/his shop within the same acquisition zone $o$;

- the wholesaler (or distributor) delivers the freight within the same attraction zone $d$;

- the carrier brings all the goods inside the same acquisition zone $o$ and delivers them within the same attraction zone $d$.

The number of vehicles of type $v$ moving freight type $s$ on the $o d$ pair in time period $h$ with restocking type $r, V C_{o d}^{s h}[v \tau r]$, can be expressed as:

$$
V C_{o d}^{s h}[v \tau r]=N D_{o d}^{s h}[v \tau r] / n d_{o d}^{s}[v r]
$$

where

- $\quad N D_{o d}^{s h}[v \tau r]$ is delivery flow on the od pair for restocking type $r$ and vehicle type $v$, Eq. (11);

- $n d_{o d}^{s}[v r]$ is the number of stops (deliveries) per trip undertaken by restocking type $r$ using vehicle type $v$; this number of stops can be expressed as:

$$
n d_{o d}^{s}[v r]=Q M T[v s] / q[r s]
$$

with

- $Q M T[v s]$, the average quantity transported by vehicle type $v$ that, for example, can be directly estimated by driver interviews;

- $q[r s]$, the average delivered freight quantity (shipment size), Eq. (8).

\subsubsection{Micro-simulation Approach}

The micro-simulation approach uses microsimulation and optimization models in order to simulate the different strategies for urban distribution done by a representative user belonging to different decision-maker categories. This user can be extracted from the whole population of each category using sample enumeration methods. In fact, using the sample enumeration method, it is assumed that the whole population can be represented by a random sample of individuals (decision-makers) extracted from it. The sample enumeration method allows significant flexibility in the use of models, since the attributes considered might include variables related to the decision-maker for which it is difficult to obtain mean values over the whole population or sub-populations. The micro-simulation approach can be characterized by the following steps:

- extraction of a random sample of users (decision-makers; e.g., retailer, wholesaler, carrier);

- definition of a distribution strategy for the considered decision-maker;

- urban freight distribution strategy simulation that consists of simulating the restocking tours (journeys) undertaken by each type of decision-maker; this step could use models developed for vehicle routing problems in the field of operational research;

- extension of the obtained results to the whole population.

The reader should note that this approach represents the frontier of the research in the field of urban freight transport and logistics.

\section{Application to a Real Case}

The described modeling approach has been specified, calibrated and validated to the city of Rome. Study area has been divided into 99 traffic zones by considering different levels of details that increase with their closeness to the inner area of the city (Fig. 3).

The focus regards the inner city area in order to analyze the restocking process of the area $\left(6 \mathrm{~km}^{2}\right)$, with more than 50,000 inhabitants and less than 24,000 employees related to trade. Access is allowed exclusively to vehicles with certain emissions characteristics (no access to pre-Euro vehicles) and 


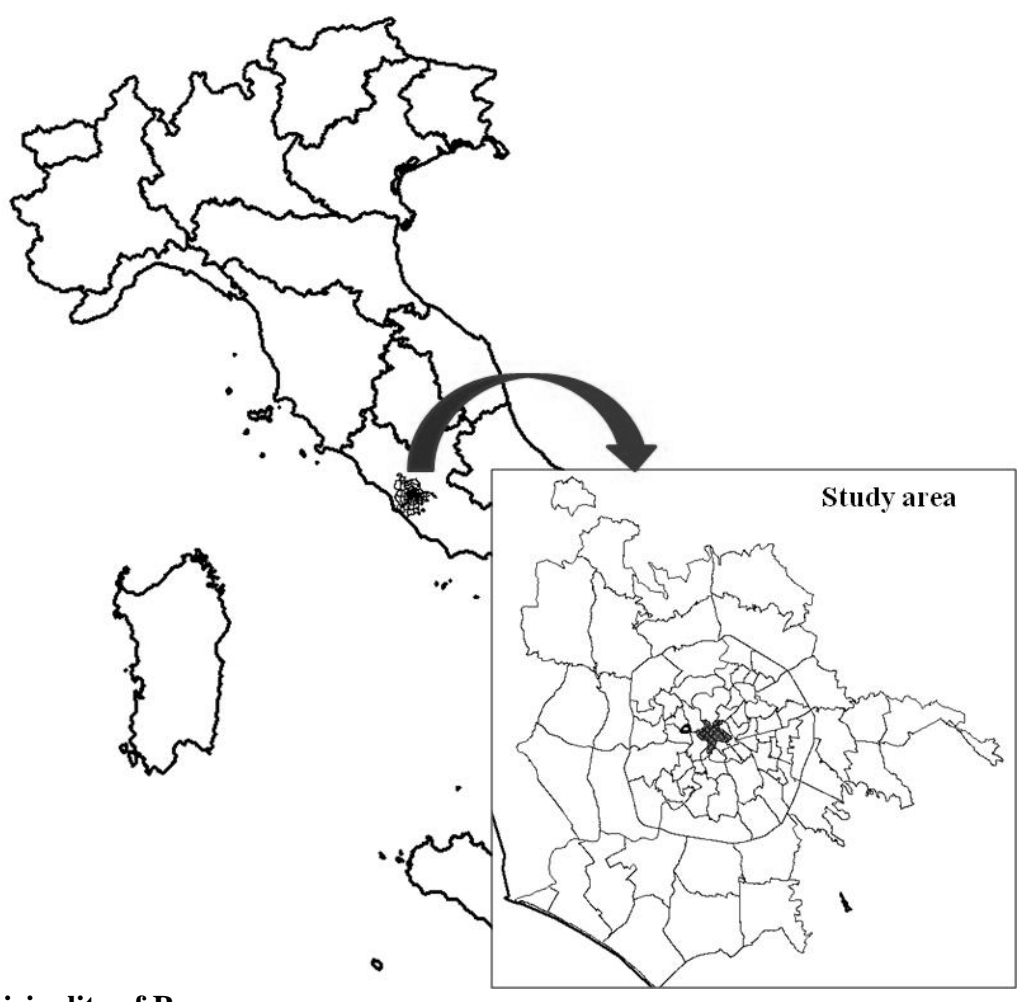

Fig. 3 Study area: municipality of Rome.

with a gross laden weight of less than 3.5 tones. The access is also allowed to vehicles with a gross laden weight less than 8.5 tones only in the night hours and is restricted to some specific roads. The modeling system has been developed in order to support the municipality of Rome in the ex-ante assessment of city logistics measures to be implemented in the next future.

The study has been supported by some surveys carried out in 2008 in the inner city area of Rome:

- traffic counts of commercial and private vehicles, and more than 500 interviews to truck drivers to investigate the supply chain of freight distribution;

- more than 600 interviews to retailers in order to obtain information about retail trade in the study area for each freight type.

These surveys revealed that the main freight type moved in the study area is food, household, and health products (about 65\%), and that distribution has two peak periods: one in the morning (8:00 to 10:00 a.m.) and one in the afternoon (3:00 to 4:00 p.m.). The incidence of freight vehicles is about $6 \%$ (about
14,000 vehicles per day) and the freight traffic is composed of goods vehicles with gross laden weight of:

- $\quad$ less than 1.5 tons $(57 \%)$,

- within 1.5 and 3.5 tons (33\%),

- $\quad$ than 8.5 tons $(10 \%)$.

The composition of freight flows is given in Table 1 . The study area is a trading area that is mainly interested by attraction freight flows. The analysis highlights freight movements in the study area for about 15,000 tons per day. The $36 \%$ consists of food (about 16\% is directed to restaurants and bars, and $14 \%$ to retailer) and the remaining $70 \%$ is made of other end-consumer products (e.g., household and health products).

The specification and calibration of the sub-models presented in the section 3 is here reported. Models have been calibrated using the generalized least squares (GLS) estimator within the classic theory of statistical inference. The presented models are the result of several specifications and calibrations based on different combinations of possible attributes. In the 
Table 1 Revealed freight flow distribution.

\begin{tabular}{lcc}
\hline & $\begin{array}{c}\text { Emitted } \\
{[\mathrm{t} / \mathrm{g}]}\end{array}$ & $\begin{array}{c}\text { Attracted } \\
{[\mathrm{t} / \mathrm{g}]}\end{array}$ \\
\hline Foodstuffs & 34 & 5234 \\
Home accessories & 88 & 2864 \\
Stationery & 31 & 2476 \\
Clothing & 38 & 1075 \\
Building Materials & - & 468 \\
Household and personal hygiene & 0.1 & 207 \\
Other goods & 3 & 2175 \\
Total & 194.1 & 14499 \\
\hline
\end{tabular}

following models that performed the best statistical significances are reported.

\subsection{Quantity OD Flows}

Referring to modeling system proposed in Section 3, attraction models of aggregate regression type have been specified and calibrated. The average quantity of freight type $s$ attracted by zone $d$ in time period $h$ (e.g., a day) can be expressed as

$$
Q_{d}^{s}=\beta_{A D}^{S} \cdot A D_{d}^{s}+\beta_{A S A}^{S} \cdot A S A_{d}[\mathrm{t} / \mathrm{day}]
$$

where

- $A D_{d}^{s}$ is the total number of employees in zone $d$ related to freight type $s$;

- $A S A_{d}$ is a dummy variable introduced in order to measure the different power of selling in zone $d$ with high shop density; it is equal to 1 if ratio between retailer employees and resident in the zone $d$ is higher than $35 \%$.

Table 2 reports values of $\beta_{i}^{\mathrm{s}}$ parameters calibrated for the seven freight types of Table 1. All parameters are correct in sign and are statistically significant as shown by $t$-student values. The capability of models to reproduce the revealed values is shown by values of $R^{2}$ similar to those reported in the literature.

Results highlight that for all types of freight the variable $A S A_{d}$ is statistically significant and its weight is not particularly high in the attracted freight estimation (especially for large zones).

In order to know the origin of freight for a given attraction zone $d$, gravitational models have been specified and calibrated. In the application, this class of models is pretty used and has given goods results. However, these models can recast in a multinomial logit structure. It aims at estimating $p[o / d s h]$, that is the share of freight type $s$ attracted by zone $d$ in time period $h$ coming from zone $o$ (e.g., places where production place/firm, distribution centre, warehouse, etc. are located) as:

$$
p[o / d s h]=\left(A I_{o}^{s}\right)^{\beta_{1}} \cdot C_{o d}^{\beta_{2}} / \sum_{o^{\prime}}\left(A I_{o^{\prime}}^{s}\right)^{\beta_{1}} \cdot C_{o^{\prime} d}^{\beta_{2}}
$$

where

- $A I_{o}{ }^{\mathrm{s}}$ is number of warehouse employees of zone $o$ for freight type $s$;

- $\quad C_{o d}$ is the length of travel trip between $o$ and $d$;

- $\quad \beta_{1}$ and $\beta_{2}$ are parameters to be calibrated.

Table 3 reports calibration results obtained for the acquisition model. Even if acquisition models have been calibrated for all freight types before recalled, similar results have been obtained. For this reason, Table 3 reports two set of parameters: the first for foodstuffs and the latter for other freight types. By analyzing results of Table 3 it is possible to point out that the number of employees has a high weight for foodstuffs, while the weight of travel cost (travel distance) plays at same way. The $R^{2}$ values are similar to those reported in literature.

\subsection{Restocking-type OD Flows}

In order to characterized the OD flows in terms of restocking types, a statistic-descriptive restocking model has been specified and calibrated. It allows to obtain the restocking share, $p[r / o d s h]$, as reported in Table 4 for the different restocking and freight types. By analyzing results of Table 4 it is possible to point out that the restocking in own account by sender (restocking center) has a share of $49 \%$; this percentage increase over $60 \%$ for foodstuffs and stationery.

\subsection{Delivery OD Flows}

In order to convert the OD matrices from quantities to deliveries, the average delivered quantity, $q[r s]$, has been estimated. Table 5 reports the different delivery 
Table 2 Attraction models: calibration results [t/day].

\begin{tabular}{cccccccc}
\hline & Foodstuffs & $\begin{array}{c}\text { Home } \\
\text { accessories }\end{array}$ & Stationery & Clothing & $\begin{array}{c}\text { Household } \\
\text { Personal hygiene }\end{array}$ & Building & Other goods \\
\hline$\beta_{A D}^{s}$ & 0.06 & 1.6 & 2.9 & 0.1 & 0.1 & 1.3 & 1.2 \\
(t-student) & $(1.89)$ & $(2.52)$ & $(1.85)$ & $(2.99)$ & $(1.85)$ & $(8.93)$ & $(3.48)$ \\
$\beta_{\text {ASA }}$ & 599.7 & 240.7 & 311.28 & 134.5 & 41.7 & $(2.35)$ & 0.51 .1 \\
$(\mathrm{t}$-student) & $(5.96)$ & $(2.53)$ & $(4.90)$ & $(3.18)$ & 0.79 & 0.89 & $(3.53)$ \\
$\mathrm{R}^{2}$ & 0.91 & 0.79 & 0.89 & 0.75 & & 0.80 \\
\hline
\end{tabular}

Table 3 Acquisition models: calibration results.

\begin{tabular}{ccc}
\hline & Foodstuffs & Remaining goods \\
\hline$\beta_{1}$ & 2.1 & 0.13 \\
$(t$-student $)$ & $(1.94)$ & $(2.63)$ \\
$\beta_{2}$ & -0.05 & -0.08 \\
$(t$-student $)$ & $(1.85)$ & $(2.80)$ \\
$\mathrm{R}^{2}$ & 0.45 & 0.52 \\
\hline
\end{tabular}

Table 4 Restocking models: revealed shares.

\begin{tabular}{lcccc}
\hline & Retail & $\begin{array}{c}\text { Restocking } \\
\text { centre }\end{array}$ & \multicolumn{2}{c}{ Carrier Total } \\
\hline Foodstuffs & $15 \%$ & $61 \%$ & $24 \%$ & $100 \%$ \\
Home Accessories & $31 \%$ & $46 \%$ & $23 \%$ & $100 \%$ \\
Stationery & $11 \%$ & $65 \%$ & $24 \%$ & $100 \%$ \\
Clothing & $11 \%$ & $42 \%$ & $47 \%$ & $100 \%$ \\
Building Materials & $6 \%$ & $40 \%$ & $54 \%$ & $100 \%$ \\
Household and personal \\
hygiene & $9 \%$ & $22 \%$ & $69 \%$ & $100 \%$ \\
Other & $28 \%$ & $21 \%$ & $51 \%$ & $100 \%$ \\
Total (average share) & $20 \%$ & $49 \%$ & $31 \%$ & $100 \%$ \\
\hline
\end{tabular}

size (shipment size) obtained by surveys for the considered freight types. The average quantity varies from about 0.5 tons for retailer in own account to 0.35 tons of carrier (third parties); this result is justified by the fact that retailers in own account are characterized by a lower number of stops/deliveries. Last column of table reports the average number of deliveries for each freight type. The high values are relative to foodstuffs and household and personal hygiene products (daily consumption products).

\subsection{Delivery OD Flows for Time Slice}

The delivery OD flows can be characterized for time slice $\tau$. In many cities around the world, including our test case, time is constrained by governance regulations: the public authorities define one or two time windows (e.g., one in the morning between 9:00-11:00 a.m. and one in the afternoon). It determines that all transport service types have to respect the same time constraints. Referring to data collected in the city of Rome, it emerges that for many freight types more than $70 \%$ of deliveries refer to the morning period (Table 6).

\subsection{Delivery OD Flows for Vehicle Type}

The vehicle type share has been estimated by collected data. Surveys carried out to truck driver at study area borders allowed to identify origins and destinations of journeys, as well as their features (e.g., vehicle type, restocking type and average load). Table 7 reports the estimated vehicle type shares and the relative average transported quantities for the following vehicle types $v$ :

- goods vehicles with transportable quantity less than 1.5 tons (LGV),

- goods vehicles with transportable quantity more than 1.5 tons (MGV).

Analyzing data of Table 7, we can see that about the $60 \%$ of the whole transport pertains to trucks with capacity higher than 1.5 tons, which move an average load of about 0.76 tons per vehicle (load factor near $50 \%$ ). Other type of trucks represent about the $40 \%$ of the whole but their average transported quantity is about twice more (1.44 tons) than that of light goods vehicles. Analyzing the results in terms of restocking types, it is possible to highlight that more than $60 \%$ of retailers and carriers use light goods vehicles, while restocking center uses at same way light and medium goods vehicles. 
Table 5 Delivery size: revealed average quantity [tons/delivery].

\begin{tabular}{lccccc}
\hline & Retail & Restocking center & Carrier & Total (average quantity) & Average no. of delivery \\
\hline Foodstuffs & 0.389 & 0.367 & 0.232 & 0.320 & 2.4 \\
Home Accessories & 1.197 & 0.982 & 0.611 & 0.902 & 1.8 \\
Stationery & 0.569 & 0.632 & 0.412 & 0.547 & 1.9 \\
Clothing & 0.238 & 0.306 & 0.275 & 0.279 & 2.1 \\
Building Materials & 0.141 & 0.395 & 0.787 & 0.424 & 1.7 \\
Household and personal hygiene & 0.300 & 0.129 & 0.196 & 0.180 & 2.2 \\
Other & 0.423 & 0.394 & 0.497 & 0.320 & 1.9 \\
Total (average) & 0.507 & 0.475 & 0.345 & 0.429 & 2.1 \\
\hline
\end{tabular}

Table 6 Time distribution: revealed shares.

\begin{tabular}{lcccccc}
\hline & before 9 am & 9 am-11 am & 11 am - 1 pm & 1 pm-4 pm & after 4 pm & Total \\
\hline Foodstuffs & $30 \%$ & $40 \%$ & $24 \%$ & $6 \%$ & $0 \%$ & $100 \%$ \\
Home Accessories & $30 \%$ & $37 \%$ & $17 \%$ & $13 \%$ & $3 \%$ & $100 \%$ \\
Stationery & $34 \%$ & $50 \%$ & $9 \%$ & $7 \%$ & $1 \%$ & $100 \%$ \\
Clothing & $23 \%$ & $51 \%$ & $15 \%$ & $11 \%$ & $1 \%$ & $100 \%$ \\
Building Materials & $38 \%$ & $42 \%$ & $10 \%$ & $4 \%$ & $5 \%$ & $100 \%$ \\
Household and personal hygiene & $47 \%$ & $32 \%$ & $19 \%$ & $2 \%$ & $0 \%$ & $100 \%$ \\
Other & $27 \%$ & $31 \%$ & $21 \%$ & $20 \%$ & $0 \%$ & $100 \%$ \\
Total (average) & $34 \%$ & $40 \%$ & $16 \%$ & $9 \%$ & $1 \%$ & $100 \%$ \\
\hline
\end{tabular}

Table 7 Vehicle share and average transported quantity [t/veh].

\begin{tabular}{|c|c|c|c|c|c|c|}
\hline Freight type & Vehicle type & Retail & Restocking centre & Carrier & Total (average share) & QMT $[\mathrm{v}, \mathrm{s}][$ tons $]$ \\
\hline \multirow{3}{*}{ Foodstuffs } & LGV & $92 \%$ & $62 \%$ & $75 \%$ & $70 \%$ & 0.75 \\
\hline & MGV & $8 \%$ & $38 \%$ & $25 \%$ & $30 \%$ & 1.13 \\
\hline & Total & $100 \%$ & $100 \%$ & $100 \%$ & $100 \%$ & 0.92 \\
\hline \multirow{3}{*}{$\begin{array}{l}\text { Home } \\
\text { Accessories }\end{array}$} & LGV & $58 \%$ & $37 \%$ & $69 \%$ & $51 \%$ & 1.22 \\
\hline & MGV & $42 \%$ & $63 \%$ & $31 \%$ & $49 \%$ & 2.38 \\
\hline & Total & $100 \%$ & $100 \%$ & $100 \%$ & $100 \%$ & 1.60 \\
\hline \multirow{3}{*}{ Stationery } & LGV & $55 \%$ & $62 \%$ & $66 \%$ & $62 \%$ & 0.92 \\
\hline & MGV & $45 \%$ & $38 \%$ & $34 \%$ & $38 \%$ & 1.34 \\
\hline & Total & $100 \%$ & $100 \%$ & $100 \%$ & $100 \%$ & 1.00 \\
\hline \multirow{3}{*}{ Clothing } & LGV & $100 \%$ & $54 \%$ & $66 \%$ & $65 \%$ & 0.53 \\
\hline & MGV & $0 \%$ & $46 \%$ & $34 \%$ & $35 \%$ & 0.97 \\
\hline & Total & $100 \%$ & $100 \%$ & $100 \%$ & $100 \%$ & 0.62 \\
\hline \multirow{3}{*}{$\begin{array}{l}\text { Building } \\
\text { materials }\end{array}$} & LGV & $43 \%$ & $64 \%$ & $12 \%$ & $35 \%$ & 0.55 \\
\hline & MGV & $57 \%$ & $36 \%$ & $88 \%$ & $65 \%$ & 0.91 \\
\hline & Total & $100 \%$ & $100 \%$ & $100 \%$ & $100 \%$ & 0.70 \\
\hline \multirow{3}{*}{$\begin{array}{l}\text { Household and } \\
\text { hygiene products }\end{array}$} & LGV & $100 \%$ & $76 \%$ & $100 \%$ & $95 \%$ & 0.43 \\
\hline & MGV & $0 \%$ & $24 \%$ & $0 \%$ & $5 \%$ & 0.31 \\
\hline & Total & $100 \%$ & $100 \%$ & $100 \%$ & $100 \%$ & 0.42 \\
\hline \multirow{3}{*}{ Other goods } & LGV & $45 \%$ & $61 \%$ & $50 \%$ & $51 \%$ & 0.59 \\
\hline & MGV & $55 \%$ & $39 \%$ & $50 \%$ & $49 \%$ & 1.68 \\
\hline & Total & $100 \%$ & $100 \%$ & $100 \%$ & $100 \%$ & 0.82 \\
\hline \multirow{3}{*}{ All goods } & LGV & $64 \%$ & $56 \%$ & $63 \%$ & $60 \%$ & 0.76 \\
\hline & MGV & $36 \%$ & $44 \%$ & $37 \%$ & $40 \%$ & 1.44 \\
\hline & Total & $100 \%$ & $100 \%$ & $100 \%$ & $100 \%$ & 0.92 \\
\hline
\end{tabular}



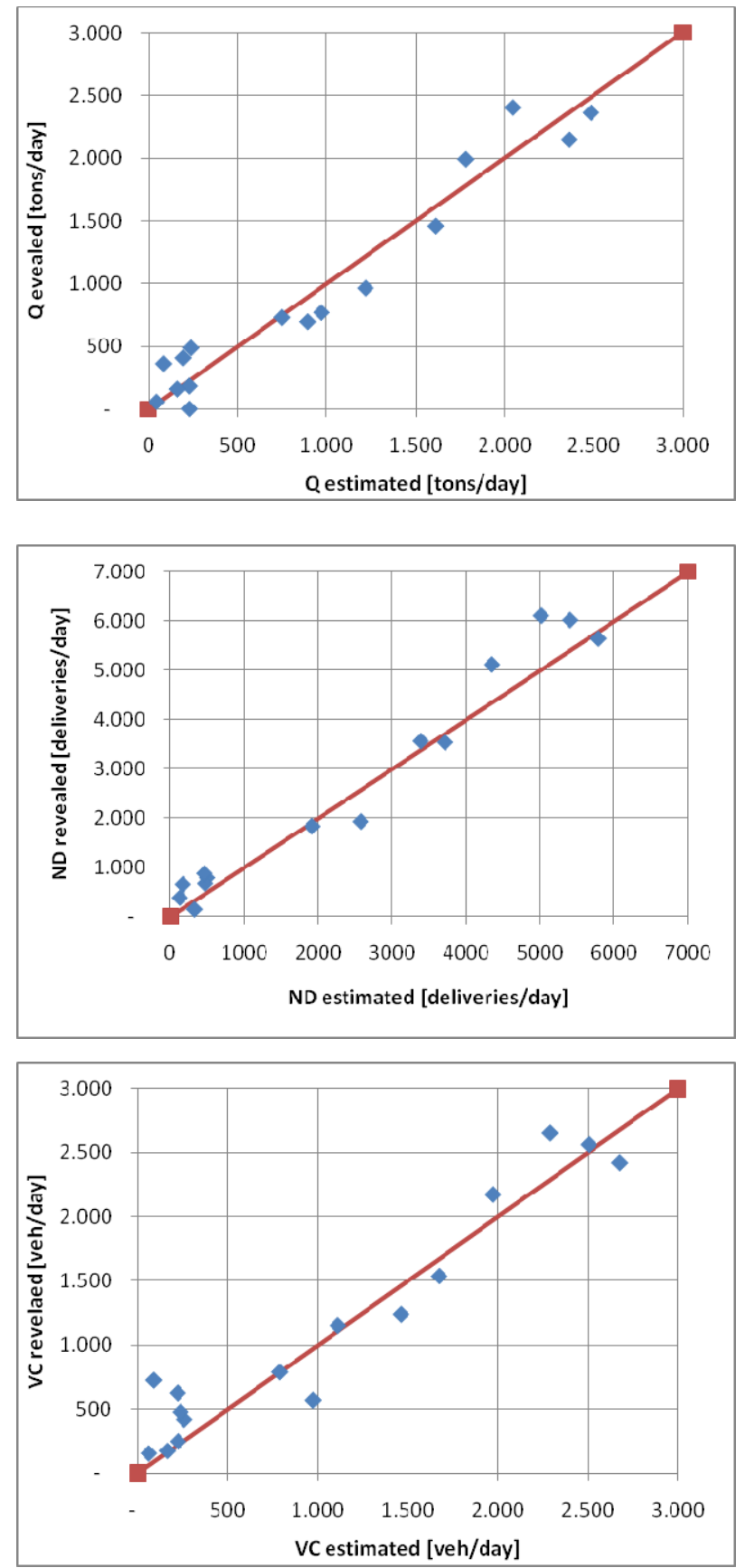

Fig. 4 Demand modeling calibration and validation: revealed $v s$ estimated flows.

\subsection{Vehicle OD Flows}

Referring to the two approaches detailed in the section 3, we analyzed the possibility to obtain the vehicle OD flows using the average quantity approach. Under this assumption, the number of vehicles of type $v$ moving freight type $s$ on the $o d$ pair in time period $h$ with restocking type $r, V C_{o d}^{s h}[v \tau r]$, can be expressed by Eq. (15). The Fig. 4 shows the results obtained by the application of the developed modeling system. The results have been reported in terms of commodity, delivery and vehicle. Referring to the aggregate results of the validation phase, the modeling system allows us to reproduce the actual situation of freight transport in the inner city area of Rome, as summarized in the following:

- commodity flows: revealed about 14,499 tons/day vs 14,296 tons/day by model application $(-1.4 \%)$;

- delivery flows: revealed about 34,246 deliveries/day vs 34,190 deliveries/day by model application $(-0.2 \%)$;

- vehicle flows: revealed about 15,773 trucks/day vs 15,718 trucks/day by model application $(-0.3 \%)$.

\section{Conclusions}

Congestion in urban areas, restrictions applied to vehicle movement for sustainability issues, as well a the reduction of accessibility of particular urban centers, have been forwarded researchers to investigate solutions to define city logistics measures to reduce the negative effects of freight transport. For this reason it is important to have methods and models capable to simulate effects of measures before implementing them in the framework of an ex-ante assessment of possible impacts.

This paper presented a modeling system developed in order to support ex-ante assessment of city logistics measures. The freight modeling system has been specified and calibrated on the basis of a real test case (the city of Rome). Models have been specified within the commodity-based modeling approach because it allows us to capture quite well the mechanisms underlying freight transport demand. In order to convert the quantity freight flows to vehicles a further unit of reference has been introduced. This unit of reference concerns deliveries and it allows us to 
support and to follow the definition of tours/journeys undertaken for restocking.

The modeling system has been specified through easy-to-capture variables (especially for its forecasting use) represented by LoS attributes and aggregate socio-economic variables, such as number of employees.

Regarding the calibration, results show that all obtained parameters are statistically significant in both expected sign and validation statistics.

This system of models can be successfully used for the estimation of urban freight flows by road in the initial assessment of future scenarios, as well as to calculate the impacts due to new city logistics measure implementation.

Further developments of this research mainly regard three main topics: the possibility to analyze how city logistics measures can influence the delivery size (delivery OD flow step), the possibility to develop and test other approaches in order to convert freight flows into truck tours, as well as to move the modeling specification and calibration from the proposed descriptive approach to the behavioral one. In particular, the attention can be focused on restocking and vehicle type choice models. The restocking model could be an useful tool to investigate how a choice of restocking type can influence the definition of tours (trip-chains) and the used vehicle. In fact, the use of a particular restocking type could influence the average size of shipment and, hence, the type of vehicle to be used. Referring to vehicle type model, in literature some models were developed in order to simulate the choice of private cars, but there are few models for the simulation of truck holding choice. This model could be specified and calibrate according to Random Utility Theory where the systematic utility could be considered as a function of some attributes related to the dimension of wholesaler (e.g., employees), shipment (e.g., frequency, length of journey) and vehicle features (e.g., payload). Other developments could aim to develop this modeling system within a
Decision Support System which could be a useful tool for appraising impacts of urban freight transport measures and policies.

\section{Acknowledgments}

Authors would like to thank Dr. Silvia Galuppi for her support in the analysis of the dataset.

\section{References}

[1] M. Browne, J. Allen, A. Woodburn, D. Patier and J. L. Routhier, Comparison of urban freight data collection in European countries, in: Proceedings of the 11th World Conference on Transport Research, Berkeley CA, U.S.A., 2007.

[2] COST 321, Urban goods transport, Final report of the action, Transport Research, European Commission Directorate General Transport, Belgium, 1998.

[3] City Ports, City Ports — project interim report, Emilia-Romagna Region, Bologna, Italy, 2005.

[4] BESTUFS, BESTUFS - Good practice guide on urban freight, BESTUFS Consortium, available online at: http://www.bestufs.net, 2007.

[5] F. Russo and A. Comi, Measures for sustainable freight transportation at urban scale: Expected goals and tested results in Europe, Journal of Urban Planning and Development 137 (2) (2011) 142-152.

[6] K. W. Ogden, Urban Goods Movement, Ashgate, Hants, England, 1992.

[7] A. C. Regan and R. A. Garrido, Modeling freight demand and shipper behaviour: State of the art, future directions, in: D. Hensher (ed.), Travel Behaviour Research: The Leading Edge, Pergamon, Amsterdam, The Netherlands, 2001.

[8] C. Ambrosini and J. Routhier, Objectives, methods and results of surveys carried out in the field of urban freight transport: An international comparison, in: Proceedings of the 9th World Conference on Transport Research, Seoul, South Korea, 2001.

[9] C. Ambrosini, B. Meimbresse, J. Routhier and H. Sonntag, Urban freight policy-oriented modelling in Europe, in: E. Taniguchi and R. G. Thompson (eds.), Proceedings of City Logistics V Kyoto, Japan, 2007.

[10] J. Y. J. Chow, C. H. Yang and A. C. Regan, State-of-the art of freight forecast modeling: Lessons learned and the road ahead, Transportation 37 (6) (2010) 1011-1030.

[11] E. Taniguchi and R. G. Thompson, Message from the guest editors, Procedia - Social and Behavioral Sciences 2 (3) (2010) 5897.

[12] A. Comi, P. Delle Site, F. Filippi and A. Nuzzolo, Urban freight transport demand modelling: A state of the art, 
European Transport/Trasporti Europei 51, ISTIEE, Trieste, Italy, 2012.

[13] F. Spielberg and S. A. Smith, Service and supply trips at federal institutions in Washington, DC area, Transportation Research Record 834, 1981.

[14] J. D. Hunt and K. J. Stefan, Tour-based microsimulation of urban commercial movements, Transportation Research Part B: Methodological 41 (9) (2007) 981-1013.

[15] Q. Wang and J. Holguin-Veras, Tour-based entropy maximization formulations of urban freight demand, in: Proceedings of the 88th Transportation Research Board Annual Meeting, Washington DC, 2009.

[16] A. Nuzzolo, U. Crisalli and A. Comi, A modelling system for urban freight movements, in: Proceedings of the 11th International Conference of Hong Kong Society for Transportation Studies, Hong Kong, China, 2006.

[17] F. Russo and A. Comi, Models for joining consumer trips and goods movements at urban scale, in: Proceedings of the 88th Transportation Research Board Annual Meeting, Washington DC, U.S.A., 2009.

[18] P. Raothanachonkun, K. Sano, W. Wisetjindawat and S. Matsumoto, Truck trips origin destination using commodity based model combined with an empty trip model, in: Proceedings of the 86th Transportation Research Board Annual Meeting, Washington DC, U.S.A., 2007.

[19] Q. Wang and J. Holguin-Veras, An investigation on the attributes determining trip chaining behavior in hybrid micro-simulation urban freight models, in: Proceedings of the 87th Transportation Research Board Annual Meeting, Washington DC, U.S.A., 2008.

[20] A. Nuzzolo, U. Crisalli and A. Comi, A restocking tour model for the estimation of O-D freight vehicle in urban areas, Procedia Social and Behavioral Sciences 20 (2011) 140-149.

[21] N. Oppenheim, Urban Travel Demand Modeling, John Wiley \& Son, New York, 1994.

[22] J. Munuzuri, J. Larraneta, L. Onieva and P. Cortes, Estimation of an origin-destination matrix for urban freight transport: Application to the city of Seville, in: E. Taniguchi and R. G. Thompson (eds.), Logistics Systems for Sustainable Cities - Proceedings of 3rd Conference on City Logistics, 2004.

[23] A. Nuzzolo, U. Crisalli and A. Comi, Metropolitan freight distribution by railways, in: E. Taniguchi and R. G. Thompson (eds.), Innovations in City Logistics, Nova Science Publishers, Hauppauge NY, U.S.A., 2008.

[24] F. Russo and A. Comi, A modelling system to simulate goods movements at an urban scale, Transportation 37 (6) (2010) 987-1009.

[25] J. L. Routhier and F. Toilier, FRETURB V3: A policy oriented software of modelling urban goods movements, in: Proceedings of the 11th World Conference on Transport Research, Berkeley CA, U.S.A., 2007.

[26] H. J. Quak and M. B. M. de Koster, Exploring retailers' sensitivity to local sustainability policies, Journal of Operational Management 25 (6) (2007) 1103-1122.

[27] N. Ando and E. Taniguchi, An Experimental study on the performance of probabilistic vehicle routing and scheduling with ITS, in: E. Taniguchi and R. G. Thompson (eds.), Recent Advances in City Logistics, Elsevier Ltd., United Kingdom, 2006.

[28] F. Russo, A. Vitetta and A. Comi, Estimation of target time distribution for agri-food products by road transport, in: N. H. M. Wilson and A. Nuzzolo (eds.), Schedule-Based Modeling of Transportation Networks: Theory and Applications, Springer Science + Business Media, 2009. 